\title{
Synthesis and Photophysical Properties of 9,10-Disubstituted Anthracenes
}

\author{
Roberto Pizzoferrato1*, Pietro Tagliatesta², Carlo Schillaci², Paolo Prosposito', \\ Roberta De Angelis ${ }^{1}$ \\ ${ }^{1}$ Dipartimento di Ingegneria Industriale, Università di Roma Tor Vergata, Roma, Italy \\ ${ }^{2}$ Dipartimento di Scienze e Tecnologie Chimiche, Università di Roma Tor Vergata, Roma, Italy \\ Email: "pizzoferrato@uniroma2.it
}

Received 11 September 2015; accepted 14 November 2015; published 17 November 2015

Copyright (C) 2015 by authors and Scientific Research Publishing Inc.

This work is licensed under the Creative Commons Attribution International License (CC BY). http://creativecommons.org/licenses/by/4.0/

(c) $\underset{\mathrm{EY}}{\text { (i) }}$ Open Access

\section{Abstract}

We report the synthesis and photophysical characterization of four 9,10-disubstituted diphenylanthracenes with specific modifications of the model backbone which involve both the 9,10 para substituents at the phenyl rings and the substitution with carbon-carbon triple bonds. The effects of such modifications on the photoluminescence and electroluminescence properties have been investigated on the basis of the diphenylanthracene molecular characteristics and in view of application to light-emitting devices. We have found that the substitution with the carbon-carbon triple bonds at the two 9,10-phenyls noticeably alters the electronic states of the reference molecule, also introducing a certain degree of sensitivity to the phenyl substituents, which improves the tunability of the optical emission. Differently, the 9,10 para substituents produce minor changes in the single-molecule properties, due to the lack of electronic conjugation across the 9,10-phenyls. However, even a single nitro substituent in the phenyl para position produces the formation of excimers, which appreciably reduces the optical quantum efficiency. These properties are maintained in solid-state blends and simple spin-coated bilayer electroluminescent devices have been fabricated.

\section{Keywords}

Blue Material, Electroluminescence, PVK, 9,10-Diphenylanthracene, Organic Light-Emitting Devices

\section{Introduction}

In the last thirty years, anthracene derivatives have demonstrated to have a surprisingly great number of applica-

*Corresponding author.

How to cite this paper: Pizzoferrato, R., Tagliatesta, P., Schillaci, C., Prosposito, P. and De Angelis, R. (2015) Synthesis and Photophysical Properties of 9,10-Disubstituted Anthracenes. Materials Sciences and Applications, 6, 943-952.

http://dx.doi.org/10.4236/msa.2015.611095 
tions in very different fields, which range from anticancer agents [1] to fluorescence probes and chemical sensors [2] [3] and also encompassing thin-film transistors [4] and solar cells [5]. Since their first application in early organic light-emitting devices (OLED) [6], these compounds have witnessed a further rising interest due to the great chance of molecular engineering with the addition of substituent groups [7]-[11] as well as with the exploitation of less standard process, such as the triplet-triplet annihilation [12] [13]. Synthesis and investigations have especially been aimed to achieve efficient, pure and stable emission in the blue side of the spectrum as well as to accomplish tunability towards longer wavelengths and good solubility for spin-coating processing. Specifically, even though recent studies have addressed the 2,6-substituted anthracenes [9], which are less prone to face-to-face packing ( $\pi-\pi$ stacking) and consequent decrease of emission efficiency, the greatest interest has been risen by the 9,10-substituted anthracenes and especially by 9,10-disubstituted diphenylanthracene (DPA) derivatives [6] [7] [14]-[20], basing on the 95\% quantum yield of DPA itself and on the great chance of molecular engineering offered by its molecular structure. Within this framework, we have synthesized four 9,10-disubstituted diphenylanthracene derivatives with specific modifications of the model backbone, involving both 9,10 para substituents at the phenyl rings and the substitution with carbon-carbon triple bonds. The effects of such modifications on the photophysical properties and the chance of application to OLEDs have thus been investigated by photoluminescence (PL) measurements and by implementing simple bilayer electroluminescence (EL) devices.

\section{Experimental Section}

\subsection{Material Synthesis}

The molecular structure of the four synthesized 9,10-disubstituted diphenylanthracene derivatives are shown in Figure 1. In this section, in addition to the preparation of the derivatives, hereafter referred to as $\mathbf{A}, \mathbf{B}, \mathbf{C}$ and $\mathbf{D}$, all the reaction intermediates are also reported.

9,10-bis-(4-methoxyphenyl)anthracene (A): $1 \mathrm{~g}\left(3.0 \times 10^{-3} \mathrm{~mol}\right)$ of 9,10-dibromoanthracene was dissolved in $20 \mathrm{ml}$ of toluene and $2.28 \mathrm{~g}\left(1.5 \times 10^{-2} \mathrm{~mol}\right)$ of 4-methoxyphenyl boronic acid were added. To the obtained mixture, $20 \mathrm{mg}$ of $\mathrm{Pd}(\mathrm{AcO})_{2}, 40 \mathrm{mg}$ of triphenylphosphine and $5 \mathrm{ml}$ of a $1 \mathrm{M} \mathrm{Na}_{2} \mathrm{CO}_{3}$ solution were added. The mixture was deoxygenated with an argon stream for $20 \mathrm{~min}$ and refluxed for $18 \mathrm{~h}$ under nitrogen. The reaction was cooled at room temperature and $100 \mathrm{ml}$ of water were added. The solution was twice extracted with diethyl ether and after the evaporation of the solvent, the residue was purified by flash chromatography $\left(\mathrm{SiO}_{2}, 1 \%\right.$ diethyl ether/hexane mixture) and the desired compound was identified by ${ }^{1} \mathrm{H}$ NMR and mass spectra. Yield $60 \%$. m.p. $272^{\circ} \mathrm{C}-273{ }^{\circ} \mathrm{C} ;{ }^{1} \mathrm{H} \mathrm{NMR}\left(400 \mathrm{MHz}, \mathrm{CDCl}_{3}\right) \delta=7.73(\mathrm{~m}, 4 \mathrm{H}), 7.40(\mathrm{~d}, 4 \mathrm{H}, \mathrm{J}=12 \mathrm{~Hz}), 7.32(\mathrm{~m}, 4 \mathrm{H}), 7.14(\mathrm{~d}$, 4H, J = $12 \mathrm{~Hz}), 3.96(\mathrm{~s}, 6 \mathrm{H})$ : EI MS: $\mathrm{m} / z(\%)$ 390(100).<smiles>COc1ccc(-c2c3ccccc3c(-c3ccc(OC)cc3)c3ccccc23)cc1</smiles>

A<smiles>COc1ccc(-c2c3ccccc3c(-c3ccc([N+](=O)[O-])cc3)c3ccccc23)cc1</smiles>

B<smiles>COc1cccc(OC)c1C#Cc1c2ccccc2c(C#Cc2c(OC)cccc2OC)c2ccccc12</smiles>

C<smiles>COc1ccc(C#Cc2c3ccccc3c(C#Cc3ccc(OC)cc3)c3ccccc23)cc1</smiles>

D 
9-bromo-10-(4-methoxyphenyl)anthracene: $1 \mathrm{~g}\left(3.0 \times 10^{-3} \mathrm{~mol}\right)$ of 9,10-dibromoanthracene was dissolved in $20 \mathrm{ml}$ of toluene and $1.14 \mathrm{~g}\left(7.5 \times 10^{-3} \mathrm{~mol}\right)$ of 4-methoxyphenyl boronic acid were added. To the obtained mixture, $20 \mathrm{mg}$ of $\mathrm{Pd}(\mathrm{AcO})_{2}, 40 \mathrm{mg}$ of triphenylphosphine and $5 \mathrm{ml}$ of a $1 \mathrm{M} \mathrm{Na}_{2} \mathrm{CO}_{3}$ solution were added. The mixture was deoxygenated with an argon stream for $20 \mathrm{~min}$ and refluxed for $18 \mathrm{~h}$ under nitrogen. The reaction was cooled at room temperature and $100 \mathrm{ml}$ of water were added. The solution was twice extracted with diethyl ether and after the evaporation of the solvent, the residue was purified by flash chromatography $\left(\mathrm{SiO}_{2}, 1 \%\right.$ diethyl ether/hexane mixture) and the desired compound was identified by ${ }^{1} \mathrm{H}$ NMR and mass spectra. Yield $80 \%$. m.p. $187^{\circ} \mathrm{C}-188^{\circ} \mathrm{C} ;{ }^{1} \mathrm{H}$ NMR $\left(400 \mathrm{MHz}, \mathrm{CDCl}_{3}\right) \delta=8.62(\mathrm{~d}, 2 \mathrm{H}, \mathrm{J}=8.2 \mathrm{~Hz}), 7.67(\mathrm{~d}, 2 \mathrm{H}, \mathrm{J}=8.2 \mathrm{~Hz}), 7.59(\mathrm{t}, 2 \mathrm{H}$, $\mathrm{J}=6.5 \mathrm{~Hz}), 7.38(\mathrm{t}, 2 \mathrm{H}, \mathrm{J}=6.5 \mathrm{~Hz}), 7.53(\mathrm{~d}, 2 \mathrm{H}, \mathrm{J}=8.1 \mathrm{~Hz}), 7.14(\mathrm{~d}, 2 \mathrm{H}, \mathrm{J}=8.1 \mathrm{~Hz}), 3.98(\mathrm{~s}, 3 \mathrm{H}) ; \mathrm{EI} \mathrm{MS}: \mathrm{m} / \mathrm{z}(\%)$ 363(100).

9-(3-nitrophenyl)-10-(4-methoxyphenyl)anthracene (B): $1 \mathrm{~g}\left(2.8 \times 10^{-3} \mathrm{~mol}\right)$ of 9-bromo-10-(4'-methoxyphenyl)anthracene was dissolved in $20 \mathrm{ml}$ of toluene and $1.4 \mathrm{~g}\left(8.4 \times 10^{-3} \mathrm{~mol}\right)$ of 3-nitrophenyl boronic acid was added. To the obtained mixture, $20 \mathrm{mg}$ of $\mathrm{Pd}(\mathrm{AcO})_{2}, 40 \mathrm{mg}$ of triphenylphosphine and $5 \mathrm{ml}$ of a $1 \mathrm{M}$ $\mathrm{Na}_{2} \mathrm{CO}_{3}$ solution were added. The mixture was deoxygenated with an argon stream for 20 min and refluxed for $18 \mathrm{~h}$ under nitrogen. The reaction was cooled at room temperature and $100 \mathrm{ml}$ of water was added. The solution was twice extracted with diethyl ether and after the evaporation of the solvent, the residue was purified by flash chromatography $\left(\mathrm{SiO}_{2}, 5 \%\right.$ diethyl ether/hexane mixture) and the desired compound was identified by ${ }^{1} \mathrm{H} \mathrm{NMR}$ and mass spectra. Yield $60 \%$. m.p. $301^{\circ} \mathrm{C}-302^{\circ} \mathrm{C} ;{ }^{1} \mathrm{H} \mathrm{NMR}\left(400 \mathrm{MHz}, \mathrm{CDCl}_{3}\right) \delta=8.49(\mathrm{~d}, 2 \mathrm{H}, \mathrm{J}=12.2 \mathrm{~Hz})$, 7.77(m, 2H), 7.32(m, 2H), 7.67(d, 2H, J = 12.2 Hz), 7.53(m, 6H), 7.17(d, $2 \mathrm{H}, \mathrm{J}=12.2 \mathrm{~Hz}), 3.97(\mathrm{~s}, 3 \mathrm{H})$ : EI MS: $\mathrm{m} / \mathrm{z}(\%)$ 405(100).

9,10-bis-(3-nitrophenyl)anthracene: $1 \mathrm{~g}\left(3.0 \times 10^{-3} \mathrm{~mol}\right)$ of 9,10-dibromoanthracene was dissolved in $20 \mathrm{ml}$ of toluene and $2.5 \mathrm{~g}\left(1.5 \times 10^{-2} \mathrm{~mol}\right)$ of 3-nitrophenyl boronic acid were added. To the obtained mixture, $20 \mathrm{mg}$ of $\mathrm{Pd}(\mathrm{AcO})_{2}, 40 \mathrm{mg}$ of triphenylphosphine and $5 \mathrm{ml}$ of a $1 \mathrm{M} \mathrm{Na}_{2} \mathrm{CO}_{3}$ solution were added. The mixture was deoxygenated with an argon stream for $20 \mathrm{~min}$ and refluxed for $36 \mathrm{~h}$ under nitrogen. The reaction was cooled at room temperature and $100 \mathrm{ml}$ of water were added. The solution was twice extracted with chloroform and after the evaporation of the solvent, the residue was purified by flash chromatography $\left(\mathrm{SiO}_{2}, 10 \%\right.$ diethyl ether/hexane mixture) and the desired compound was identified by ${ }^{1} \mathrm{H}$ NMR and mass spectra. Yield $40 \%$. m.p. $>320^{\circ} \mathrm{C}$; ${ }^{1} \mathrm{H}$ NMR(400 MHz, $\left.\mathrm{CDCl}_{3}\right) \delta=8.51(\mathrm{~d}, 4 \mathrm{H}, \mathrm{J}=12.4 \mathrm{~Hz}), 7.69(\mathrm{~d}, 4 \mathrm{H}, \mathrm{J}=12.4 \mathrm{~Hz}), 7.58(\mathrm{~m}, 4 \mathrm{H}), 7.41(\mathrm{~m}, 4 \mathrm{H})$; EI MS: $m / z(\%) 420(100)$.

9,10-bis-[(4-methoxyphenyl)ethynyl]anthracene (C): $1 \mathrm{~g}\left(3.0 \times 10^{-3} \mathrm{~mol}\right)$ of 9,10-dibromoanthracene was dissolved in $20 \mathrm{ml}$ of dry THF and $6.5 \mathrm{~g}\left(1.5 \times 10^{-2} \mathrm{~mol}\right)$ of 4-ethynyl-methoxybenzene were added. To the obtained mixture, $0.2 \mathrm{ml}$ of $10 \%$ tetrabutylammonium fluoride THF solution was added. The homogeneous solution was deoxygenated with an argon stream for $20 \mathrm{~min}$ after that $20 \mathrm{mg}$ of $\mathrm{Pd}\left(\mathrm{PPh}_{3}\right)_{2} \mathrm{Cl}_{2}$ were added under nitrogen. The mixture was further deoxygenate with an argon stream for 20 min and kept at $60^{\circ} \mathrm{C}$ for 12 hours. The reaction was cooled at room temperature and $100 \mathrm{ml}$ of water were added. The solution was twice extracted with chloroform and after the evaporation of the solvent, the residue was purified by flash chromatography $\left(\mathrm{SiO}_{2}, 30 \%\right.$ dichlomethane/hexane mixture) and the desired compound was identified by ${ }^{1} \mathrm{H}$ NMR and mass spectra. Yield 50\%. m.p. $230^{\circ} \mathrm{C}-232^{\circ} \mathrm{C} ;{ }^{1} \mathrm{H}$ NMR (400 MHz, $\left.\mathrm{CDCl}_{3}\right) \delta=8.70$ (dd, $4 \mathrm{H}, \mathrm{J}=3.4 \mathrm{~Hz}$ ), $7.73(\mathrm{~d}, 4 \mathrm{H}$, $\mathrm{J}=9.2 \mathrm{~Hz}), 7.65(\mathrm{dd}, 4 \mathrm{H}, \mathrm{J}=3.4 \mathrm{~Hz}), 7.0(\mathrm{~d}, 4 \mathrm{H}, \mathrm{J}=9 \mathrm{~Hz})$; EI MS: $\mathrm{m} / \mathrm{z}(\%) 438(100)$.

9,10-bis-[(2,6-dimethoxyphenyl)ethynyl]anthracene (D): $1 \mathrm{~g}\left(3.0 \times 10^{-3} \mathrm{~mol}\right)$ of 9,10-dibromoanthracene was dissolved in $20 \mathrm{ml}$ of dry THF and $7.47 \mathrm{~g}\left(1.5 \times 10^{-2} \mathrm{~mol}\right)$ of 2,6-dimethoxy-ethynylbenzene [21] were added. To the obtained mixture, $0.2 \mathrm{ml}$ of $10 \%$ tetrabutylammonium fluoride THF solution was added. The homogeneous solution was deoxygenated with an argon stream for 20 min after that $20 \mathrm{mg}$ of $\mathrm{Pd}\left(\mathrm{PPh}_{3}\right)_{2} \mathrm{Cl}_{2}$ were added under nitrogen. The mixture was further deoxygenate with an argon stream for 20 min and kept at $60^{\circ} \mathrm{C}$ for 12 hours. The reaction was cooled at room temperature and $100 \mathrm{ml}$ of water were added. The solution was twice extracted with chloroform and after the evaporation of the solvent, the residue was purified by flash chromatography $\left(\mathrm{SiO}_{2}, 60 \%\right.$ dichlomethane/hexane mixture) and the desired compound was identified by ${ }^{1} \mathrm{H}$ NMR and mass spectra. Yield $60 \%$ m.p. $301{ }^{\circ} \mathrm{C}-302^{\circ} \mathrm{C} ;{ }^{1} \mathrm{H} \mathrm{NMR}\left(400 \mathrm{MHz}, \mathrm{CDCl}_{3}\right) \delta=8.89(\mathrm{~m}, 4 \mathrm{H}), 7.63(\mathrm{~m}, 4 \mathrm{H})$, 7.29(t, 2H, J = 2.4 Hz)), 6.61(d, 4H, J = 1.6 Hz), 4.07(s, 12 H),: EI MS: m/z(\%) 498(100).

\subsection{Photophysical Measurements}

For the optical measurements in liquid solutions, spectroscopic-grade tetrahydrofuran (THF) was used as re- 
ceived from Sigma-Aldrich. UV-vis spectra were recorded with a Cary 50 (Varian Inc.) spectrophotometer: diluted solutions were held in silica cells with path lengths of $10 \mathrm{~mm}$ and the spectra recorded over the range 200 $600 \mathrm{~nm}$ with a $0.5 \mathrm{~nm}$ data interval and a $1 \mathrm{~nm}$ band-pass. Fluorescence spectra were recorded on a standard laboratory set-up for PL measurements equipped with a photo-multiplier (Hamamatsu R3896) placed at the output slit of a 25-cm monochromator (Oriel Cornerstone 260). Provided the diluted solutions (typical molar concentration of $10^{-6} \mathrm{M}$ ) had an absorbance of $<0.05$ in the excitation range, the fluorescence spectra were recorded by exciting the sample with the conventional $90^{\circ}$ geometry and the monochromatized output of a $\mathrm{Hg}$-Xe cw discharge lamp. Both the excitation and emission spectra were fully corrected by using the set-up calibration curve obtained with a reference black-body lamp and standard fluorophore diluted solutions. A spectral band pass of 2 $\mathrm{nm}$ was used for both the excitation and emission monochromators.

For the EL measurements, simple bilayer devices were prepared as follows. Devices were spin-coated on glass/ITO substrates (Ossila). ITO had a typical thickness of $100 \mathrm{~nm}$ and a surface resistivity of $20 \Omega / \mathrm{sq}$. The substrates were carefully cleaned with a $10 \%$ solution of $\mathrm{NaOH}$ in water at $90^{\circ} \mathrm{C}$ in an ultrasonic bath. A Poly [3,4-ethylenedioxythiophene]:Poly[styrenesulphonic acid] (PEDOT:PSS) layer was previously spin-coated on the ITO surface as hole transport layer (HTL). The emissive layer (EML) was composed by the DPA substituted species dissolved in a blend of Poly(9-vinylcarbazole) (PVK) and 2-[4-tert-Butylphenyl]-5-[4-biphenylyl]-1,3,4oxadiazole) (Butyl-PBD) purchased by Sigma Aldrich and used without further purification. Butyl-PBD acts as electron transport layer (ETL) and plays a fundamental role in enhancing EL. PVK and Butyl-PBD were dissolved in spectroscopic grade chloroform at a concentration of $20 \mathrm{mg} / \mathrm{ml}$ and $10 \mathrm{mg} / \mathrm{ml}$, respectively. DPA derivatives were added with a relative concentration of $5 \%$ by weight with respect to the PVK content. Doped PVK/Butyl-PBD layer was spin-coated on PEDOT:PSS layer at $3000 \mathrm{rpm}$ for $45 \mathrm{~s}$ and densified in vacuum at $120^{\circ} \mathrm{C}$ for $10 \mathrm{~min}$. As a final step a thin layer of about $100 \mathrm{~nm}$ of aluminum was evaporated under vacuum $(<1 \times$ $10^{-6}$ Torr) on the outer surface of the film as cathode. All fabrication processes were carried out in clean room and in controlled atmosphere. EL measurements were performed in air with a relative humidity in the range $60 \%$ - $65 \%$ without any sealing protection. PL measurements in solid-state films were carried out on the same samples as for EL, but without the deposition of the aluminum cathode.

\section{Results and Discussion}

\subsection{Absorption Spectra}

Figure 2 compares the molar absorptivity spectra of the different compounds in diluted THF solutions (molar concentration $10^{-6} \mathrm{M}$ ). It is interesting to discuss the spectra of the different derivatives by considering the respective modifications made to the reference DPA molecule along the axis linking the two 9,10-phenyls. It is, in fact, well established [3] [7] [8] [9] [18] [22] that the lower-energy UV progressions of both anthracene and DPA are determined by an allowed optical transition $\mathrm{S}_{0} \rightarrow \mathrm{S}_{1}$, assigned to $A_{1 g} \rightarrow B_{2 u}$ in group theoretical notation, with a dipole moment lying along the short axis of the molecule backbone. However, in the present compounds, neither type of substitution at the para position of 9,10-phenyls, i.e. the methoxy group in compound $\mathbf{A}$ or the nitro group in $\mathbf{B}$, seems to produce significant variations and the spectra of the two derivatives closely trace that of the reference unsubstituted DPA (Figure 2). This occurs with respect to both the typical lower-energy progression

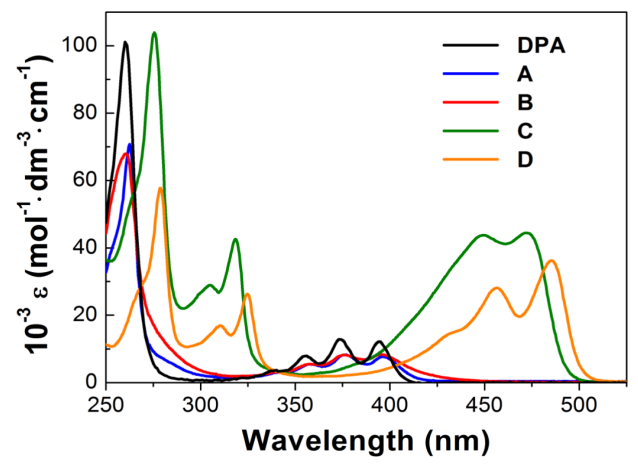

Figure 2. Absorptivity spectra of the different compounds in diluted THF solutions (molar concentration $10^{-6} \mathrm{M}$ ). 
in the range 350 - $400 \mathrm{~nm}$ and the higher-energy peak at $260 \mathrm{~nm}$ due to $\mathrm{S}_{0} \rightarrow \mathrm{S}_{2}$ transitions $\left(A_{1 g} \rightarrow B_{3 u}\right)$. A similar insensitivity to 9,10 para substituents was already reported in non-symmetric DPA derivatives with regard to the allowed $\mathrm{S}_{0} \rightarrow \mathrm{S}_{1}$ transition [7] [10] and is in agreement with theoretical calculations showing that only a small fraction of molecular orbitals extends towards the substituents [7] [19]. We suggest that the torsion of the single carbon-carbon bond due to the right-angle twisting of the two 9,10-phenyls [7] is also effective in restraining the conjugation within the anthracene backbone and preventing it from involving the different para substituents.

Conversely, quite noticeable effects are produced by the substitution of the carbon-carbon triple bonds for the single bonds linking the two 9,10-phenyls, which is performed in $\mathbf{C}$ and $\mathbf{D}$. The higher-energy peak exhibits a bathochromic shift from $260 \mathrm{~nm}$ to approximately $275 \mathrm{~nm}$ and, more significantly, the lower-energy progression is apparently split in two groups, centred at 310 and $450 \mathrm{~nm}$, respectively, which exhibit a fourfold increase of the molar absorptivity in comparison with DPA, with values as high as $\varepsilon \cong 4 \times 10^{4} \mathrm{M}^{-1} \cdot \mathrm{cm}^{-1}$. A similar splitting, with the arising of two well defined progressions centred at 325 and $390 \mathrm{~nm}$, was observed in 2,6 substituted anthracene derivatives [9] and attributed to a mixing of the two low-lying excited states $L_{a}$ and $L_{b}$ of polyacenes, with the reorientation of the dipole moments and remodulation of the respective oscillator strength. Moreover, the spectra of $\mathbf{C}$ and $\mathbf{D}$ display a certain dependence on the type and positions of the 9,10-phenyls substituents, with $\mathbf{D}$ exhibiting an appreciably higher bathochromic shift. All these findings show the greater effectiveness of the carbon-carbon triple bond in modifying the charge distribution of the anthracene backbone, also by allowing a greater extension of the molecular orbitals towards the two 9,10-phenyls due to the symmetry of triple bond against rotational motions. This could improve the $\pi$-conjugation thus explaining the general bathochromic shift of the spectral structures in $\mathbf{C}$ and $\mathbf{D}$, as well as the sensitivity to the 9,10-phenyls substituents.

In all the compounds A-D, the molar absorptivity remained constant and the absorption curves did not show any change up to values of the molar concentration as high as $10^{-3} \mathrm{M}$, which rules out the possible formation of aggregates.

\subsection{Photoluminescence Spectra}

Figure 3 displays the photoluminescence (PL) spectra of the different derivatives in diluted THF solutions (10 ${ }^{-6}$ M) excited at $\lambda_{e x}=340 \mathrm{~nm}$ while the values of the relevant photophysical parameters are reported in Table 1. The differences in the emission spectra largely reflect those of the absorption curves, showing that the molecular relaxation does not dramatically alter the different characters of the spatial distribution of electron density in the excited states. In fact, the spectra $\mathbf{A}$ and $\mathbf{B}$ are similar to that of the unsubstituted DPA, apart from a slightly larger Stokes' shift and the smearing of the vibronic bands with the complete lack of the mirror image effect. These minor differences indicate a more effective intramolecular conformational relation, which leads to slightly different relaxed excited states (RES) and could origin from a slightly greater flexibility of the molecule due to the para substituents of the 9,10-phenyls. On the other hand, the spectra of $\mathbf{C}$ and $\mathbf{D}$ are quite different from that of the unsubstituted DPA and are very similar to each other, with a large a bathochromic shift resulting in a main peak at 485 and $490 \mathrm{~nm}$, respectively, and a smaller one around $520 \mathrm{~nm}$. Similar to the case of absorption, these characteristics resemble the results reported in 2,6 substituted anthracene derivatives [9], thus confirming that the carbon-carbon triple bonds effectively alter the electronic states of the anthracene core, also by improving the conjugation along the 9,10-phenyl axis.

Table 1. Absorption peak wavelength, molar absorptivity, fluorescence peak wavelength (in solution and solid state film) and quantum yields of DPA derivative A-D.

\begin{tabular}{cccccc}
\hline Compound & $\mathrm{Abs}_{\max }(\mathrm{nm})^{\mathrm{a}}$ & $\log \varepsilon\left(\mathrm{l} \mathrm{mol}^{-1} \cdot \mathrm{cm}^{-1}\right)^{\mathrm{a}}$ & $\mathrm{PL}_{\max }$ solution $(\mathrm{nm})$ & $\mathrm{PL}_{\max }$ solid state $(\mathrm{nm})$ & $\mathrm{Q} . \mathrm{Y}$. \\
\hline A & 263 & 4.84 & 420 & 426 & 0.45 \\
B & 261 & 4.83 & 431 & 435 & 0.20 \\
C & 275 & 5.01 & 485 & 492 & 0.70 \\
D & 278 & 4.76 & 492 & 502 & 0.60 \\
\hline
\end{tabular}

${ }^{\mathrm{a}}$ Recorded in $10^{-6} \mathrm{~mol} \cdot \mathrm{L}^{-1} \mathrm{THF}$ solution; brecorded in $5 \%$ blends with PVK. 


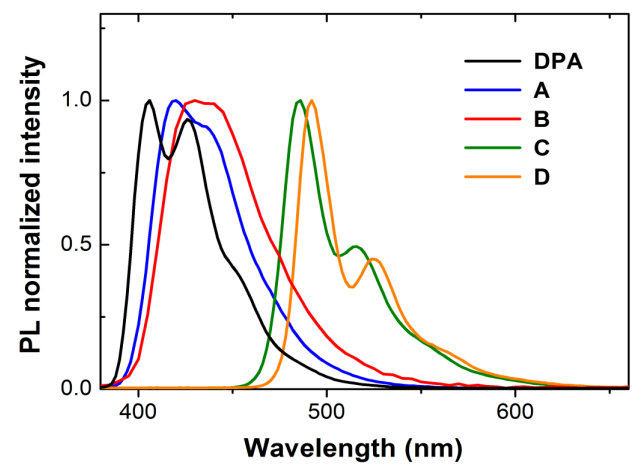

Figure 3. PL spectra of the different derivatives in diluted THF solutions $\left(10^{-6} \mathrm{M}\right)$ excited at $\lambda_{e x}=340 \mathrm{~nm}$.

Moreover, when $\mathbf{C}$ and $\mathbf{D}$ are excited at either the absorption group centred at 310 and the one at $450 \mathrm{~nm}$, respectively, the same PL spectra around $500 \mathrm{~nm}$ are observed indicating that the carbon-carbon triple bonds still allow an effective intramolecular relaxation. With regard to $\mathbf{A}$ and $\mathbf{B}$, however, even though the para substituents do not significantly alter the RES, thus the spectra of diluted solutions, it should be noted that the nitro substituent in $\mathbf{B}$ produces some relevant effects on the excited state, as we have found by increasing the molarity of solution. In fact, while the PL signal of DPA, A, C, and D showed a linear increase of intensity with concentration and a constant spectral profile, the spectrum of $\mathbf{B}$ featured the typical behaviour of the formation of excimers, similar to pyrene in cyclohexane [23]. Specifically, as reported in Figure 4, at molarity higher than $5 \times$ $10^{-6} \mathrm{M}$ a broad emission band appears with the peak at $600 \mathrm{~nm}$ and grows with increasing concentration at the expense of the single-molecule emission (430 nm) which decreases with concentration. Differently from pyrene, in $\mathbf{B}$ the formation of excimers, through the $\pi$-staking dimerization of two molecules, seems to originate from the peculiar electron-withdrawing nature of the nitro group, which produces two complementary effects [24]. First it withdraws significant electron density from the acene $\pi$-cloud, thus decreasing the repulsion of the $\pi$-faces. Second, it creates a significant electric dipole and favours the molecular alignment due to dipole-dipole interaction. Finally, it must play a determinant role also in the fact that $\mathbf{B}$ exhibits the lowest value of low-concentration quantum efficiency among all the derivatives (see Table 1 ), while $\mathbf{A}$ is mainly affected by the more effective relation processes in comparison to DPA, thus exhibiting half the quantum yield of the reference molecule. From this point of view, as well, the substitution with the carbon-carbon triple bond produces a noticeable effect by appreciably increasing the quantum yield of $\mathbf{C}$ and $\mathbf{D}$, beyond the value of $\mathbf{A}$.

\subsection{Solid Films and Electroluminescence}

As preliminary step towards the implementation of an electroluminescent device, we investigated the photophysical properties of thin films of PVK blended with the DPA derivatives. Figure 5 illustrates the PL spectra of a PVK film doped with different weight concentrations of $\mathbf{A}$ under excitation at $330 \mathrm{~nm}$. The curves are normalized by the absorption of the respective sample, so that they can be compared to each other and the PL intensity is an estimate of the relative quantum efficiency. The behaviour of the spectra with the concentration of $\mathbf{A}$ is typical of an energy transfer process, presumably based on a Forster resonant mechanism, since the emission band of PVK at $400 \mathrm{~nm}$ is rapidly quenched by small quantities of guest, while the PL of $\mathbf{A}$ at $430 \mathrm{~nm}$ progressively increases with the concentration. In fact, while the excitation light is absorbed by both the host and guest species, the relative emission of the guest $\mathbf{A}$ should be negligible, due to the much lower concentration in comparison to PVK, unless a noticeable energy transfer occurs from PVK to A. We note that this effect combines the large absorption of the PVK with the higher efficiency of the guest, thus effectively increasing the quantum efficiency of the film by a factor of four, approximately. Beyond a concentration of $1 \%$ by weight, the emission of $\mathbf{A}$ begins to saturate and eventually decreases due to the arising of intermolecular concentration effects. Finally, we note that the lineshape and peak position (428 nm) of PL in the solid state are very similar to those in diluted solutions (see Figure 3), which confirms the small importance of torsional motions in the relaxation processes of DPA derivatives [7].

By using the optimal weight ratio of $5 \%$, we fabricated simple bilayer electroluminescent devices with derivatives $\mathbf{A}, \mathbf{C}$ and $\mathbf{D}$, as described in paragraph 2.2. B was not used since, as expected, it exhibited a very low 


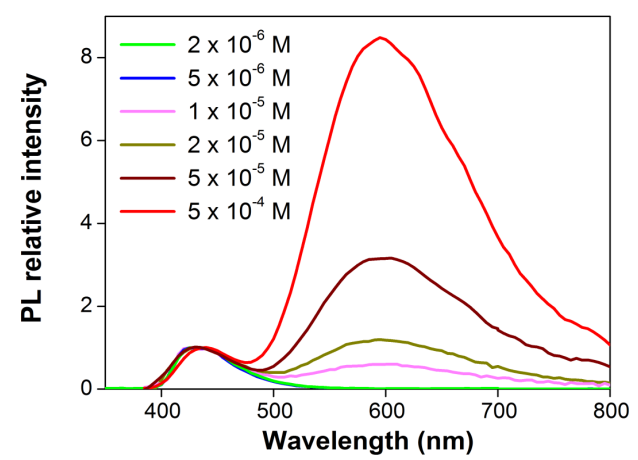

Figure 4. PL intensity of B in THF solutions as a function of the molar concentration. The curves are normalized at the maximum of the single-molecule emission $(430 \mathrm{~nm})$.

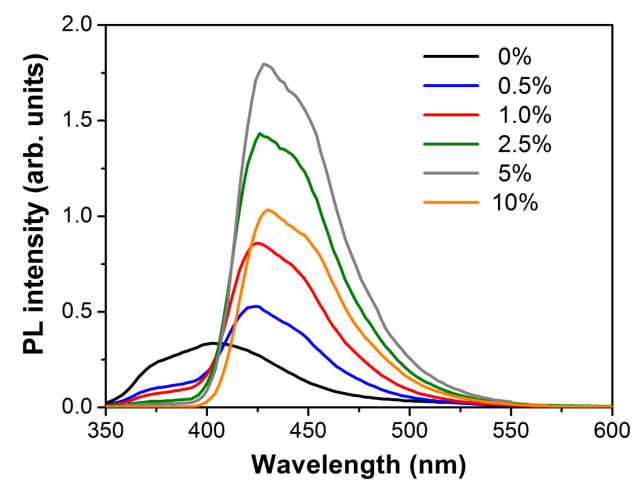

Figure 5. PL spectra of a PVK thin film doped with different concentrations of the derivative $\mathbf{A}$ under excitation with light at $330 \mathrm{~nm}$.

efficiency in the solid state due to its tendency to form excimers. Figure 6 reports the EL spectrum of a device made with a PVK:A = 95:5 doped film along with the EL signal of a neat-PVK device. The EL emission of the doped film has a maximum at $425 \mathrm{~nm}$ and is quite similar to the PL of A both in solution and as a guest in PVK film (see Figure 5), with the lack of the low-energy tail of the PVK emission. This indicates that an efficient energy transfer from PVK to $\mathbf{A}$ is still effective under an electrical excitation, even though the turn-on voltage was found to be relatively high at $15 \mathrm{~V}$ while the variation of applied voltage had no effect on the shape and the peak of the EL spectra. The slightly different profile of EL, compared to PL, underlines the different nature of the two processes and the consequent related effects. For example, it should be considered the possible presence of specific quenching sites for excitons in the EL device, due to the presence of an evaporated metal cathode.

Figure 7 reports the EL spectrum of a device made with a 5\% PVK:D doped film. The PL emission from a similar thin film deposited on ITO-coated glass, without the aluminium electrode, is also shown for comparison. We note the presence of a very effective energy transfer mechanism, both in PL and EL, since there is no trace of the emission from PVK, similar to the case of PVK:A. Moreover, the PL spectrum in the solid state is virtually identical to that of diluted liquid solution (Figure 3). This indicates that the molecular relaxation processes, which are responsible for the large Stoke shift, do not involve the torsional motions of the 9,10-phenyl moieties, as it also occurs in unsubstituted DPA [7], even in the presence of the carbon-carbon triple bonds. In this case, however, the spectral profile of EL is very similar to that of PL but with a uniform shift to longer wavelengths of $10 \mathrm{~nm}$, approximately. This effect, already observed in organic emitters [25] [26], is again due to the different nature of the two processes and could mainly origin from at least two mechanisms. First, differently from PL, in EL the injected charges migrate through the sample and will naturally move to lower energy sites even before exciton formation. Second, EL also generates triplet excitons thus directly populating the triplet states of the emitter, with the emission of red-shifted phosphorescence. Similar results were also reported for 5\% PVK:C devices (not shown). 


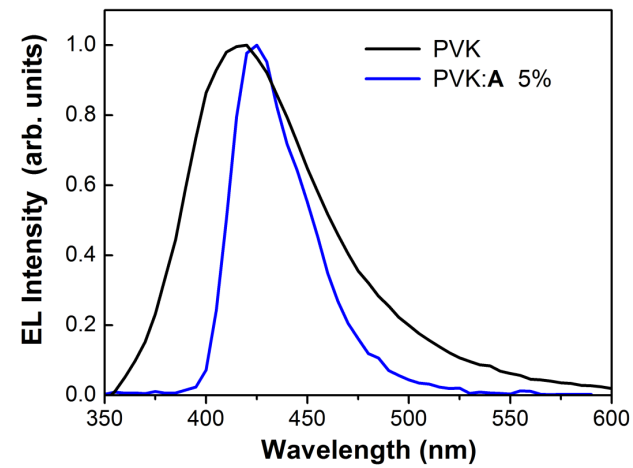

Figure 6. EL spectrum of a device made with a 5\% PVK:A doped film along with the EL of a PVK neat-film device.

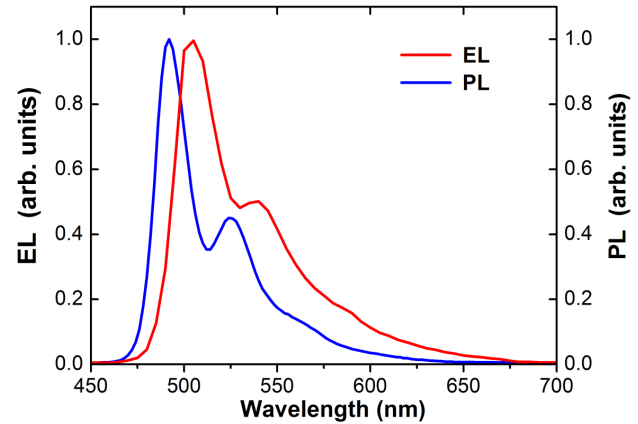

Figure 7. EL and PL spectra of a device made with a 5\% PVK:D doped film.

\section{Conclusion}

We have synthesized four 9,10-disubstituted diphenylanthracenes that emit in the blue-green region. The modifications made to the reference DPA backbone reflect on the photophysical properties of the derivatives in a way that can easily be understood on the basis of the electronic characteristics and demonstrate the versatility of the DPA backbone. Specifically, the addition of para substituents to the 9,10 phenyl rings does not significantly alter the absorption and the emission spectra of DPA, in agreement with the hypothesis that the electronic conjugation does not extend across the 9,10 phenyl rings, even though the quantum yield is appreciably reduced due to the increase of the molecular flexibility and the number of relaxation mechanisms. However, the electronwithdrawing nature of the nitro group produces the formation of excimers when the molar concentration in solution is increased beyond $10^{-5} \mathrm{M}$, which clearly prevents the use in solid-state light emission devices. Quite differently, the substitution of the carbon-carbon triple bonds for the single bonds linking the two 9,10-phenyls produces relevant effects on the electronic states, apparently by extending the conjugation across the phenyl rings. In addition to a noteworthy red shift of emission towards the green region, this increases the quantum efficiency and introduces a certain degree of sensitivity to the 9,10 phenyl substituents, which improves the tunability of the optical emission. The overall stiffness of the DPA backbone, even in the presence of the carbon-carbon triple bonds, ensures that these properties are substantially maintained in the solid state. Therefore, by exploiting an efficient energy transfer mechanism in blends with PVK as a host, the derivatives have been used to fabricate simple bilayer electroluminescent devices which exhibit a blue emission with a greater color purity and red-shifted bands in the blue-green region. We believe these results demonstrate that diphenylanthracenes, despite their simple structure and quite long-standing story of investigations, are still far from being a depleted field for molecular engineering and development of new emitting materials. In particular, the findings about the role of the carbon-carbon triple bonds provide useful suggestions for future research and applications to OLEDs. 


\section{Acknowledgements}

We thank Riccardo De Gennaro for his support and assistance during the preparation and characterization of electroluminescent devices.

\section{References}

[1] Agbandje, M., Jenkins, T.C., McKenna, R., Reszka, A.P. and Neidle, S. (1992) Anthracene-9,l O-Diones as Potential Anticancer Agents. Synthesis, DNA-Binding, and Biological Studies on a Series of 2,6-Disubstituted Derivatives. Journal of Medicinal Chemistry, 35, 1418-1429. http://dx.doi.org/10.1021/jm00086a010

[2] Becker, H.D. (1993) Unimolecular Photochemistry of Anthracenes. Chemical Reviews, 93, 145-172. http://dx.doi.org/10.1021/cr00017a008

[3] Valeur, B. (2002) Molecular Fluorescence: Principles and Applications. Wiley-VCH, Weinheim.

[4] Meng, H., Sun, F.P., Goldfinger, M.B., Jaycox, G.D., Li, Z.G., Marshall, W.J. and Blackman, G.S. (2005) High-Performance Stable Organic Thin-Film Field-Effect Transistors Based on Bis-5'-alkylthiophen-2'-yl-2,6-Anthracene Semiconductors. Journal of the American Chemical Society, 127, 2406-2407. http://dx.doi.org/10.1021/ja043189d

[5] Teng, C., Yang, X., Yang, C., Li, S., Cheng, M., Hagfeldt, A. and Sun, L. (2010) Molecular Design of AnthraceneBridged Metal-Free Organic Dyes for Efficient Dye-Sensitized Solar Cells. Journal of Physical Chemistry C, 114, 9101-9110. http://dx.doi.org/10.1021/jp101238k

[6] Shi, J. and Tang, C.W. (2002) Anthracene Derivatives for Stable Blue-Emitting Organic Electroluminescence Devices. Applied Physics Letters, 80, 3201-3203. http://dx.doi.org/10.1063/1.1475361

[7] Serevičius, T., Komskis, R., Adomėnas, P., Adomėnienė, O., Jankauskas, V., Gruodis, A., Kazlauskas, K. and Juršėnas, S. (2014) Non-Symmetric 9,10-Diphenylanthracene-Based Deep-Blue Emitters with Enhanced Charge Transport Properties. Physical Chemistry Chemical Physics, 16, 7089-7101. http://dx.doi.org/10.1039/c4cp00236a

[8] Lin, S.H., Wu, F.I. and Liu, R.S. (2009) Synthesis, Photophysical Properties and Color Tuning of Highly Fluorescent 9,10-Disubstituted-2,3,6,7-Tetraphenylanthracene. Chemical Communications, 6961-6963. http://dx.doi.org/10.1039/b912289c

[9] Zhou, X., Piland, G.B., Kurunthu, D., Dillon, R.J., Burdett, J.J. and Bardeen, C.J. (2012) The Photophysics of the 2,6 Dialkoxy Anthracenes: Evidence for Excited State Side-Chain Conformational Relaxation. Journal of Luminescence, 132, 2997-3003. http://dx.doi.org/10.1016/j.jlumin.2012.06.012

[10] Mallesham, G., Balaiah, S., Ananth Reddy, M., Sridhar, B., Singh, P., Srivastava, R., Bhanuprakash, K. and Jayathirtha Rao, V. (2014) Design and Synthesis of Novel Anthracene Derivatives as n-Type Emitters for Electroluminescent Devices: A Combined Experimental and DFT Study. Photochemical \& Photobiological Sciences, 13, 342-357. http://dx.doi.org/10.1039/c3pp50284h

[11] Kim, R., Lee, S., Kim, K.H., Lee, Y.J., Kwon, S.K., Kim, J.J. and Kim, Y.H. (2013) Extremely Deep Blue and Highly Efficient Non-Doped Organic Light Emitting Diodes Using an Asymmetric Anthracene Derivative with a Xylene Unit. Chemical Communications, 49, 4664. http://dx.doi.org/10.1039/c3cc41441h

[12] Fukagawa, H., Shimizu, T., Ohbe, N., Tokito, S., Tokumaru, K. and Fujikake, H. (2012) Anthracene Derivatives as Efficient Emitting Hosts for Blue Organic Light-Emitting Diodes Utilizing Triplet-Triplet Annihilation. Organic Electronics, 13, 1197-1203. http://dx.doi.org/10.1016/j.orgel.2012.03.019

[13] Chiang, C.J., Kimyonok, A., Etherington, M.K., Griffiths, G.C., Jankus, V., Turksoy, F. and Monkman, A.P. (2013) Ultrahigh Efficiency Fluorescent Single and Bi-Layer Organic Light Emitting Diodes: The Key Role of Triplet Fusion. Advanced Functional Materials, 23, 739-746. http://dx.doi.org/10.1002/adfm.201201750

[14] Wu, C.L., Chang, C.H., Chang, Y.T., Chen, C.T., Chen, C.T. and Su, C.J. (2014) High Efficiency Non-Dopant Blue Organic Light-Emitting Diodes Based on Anthracene-Based Fluorophores with Molecular Design of Charge Transport and Red-Shifted Emission Proof. Journal of Materials Chemistry C, 2, 7188-7200. http://dx.doi.org/10.1039/C4TC00876F

[15] Jo, W.J., Kim, K.H., No, H.C., Shin, D.-Y., Oh, S.J., Son, J.H., Kim, Y.H., Cho, Y.K., Zhao, Q.H., Lee, K.H., Oh, H.Y. and Kwon, S.K. (2009) High Efficient Organic Light Emitting Diodes Using New 9,10-Diphenylanthracene Derivatives Containing Bulky Substituents on 2,6-Positon. Synthetic Metals, 159, 1359-1364. http://dx.doi.org/10.1016/j.synthmet.2009.03.007

[16] Kim, S.K., Yang, B., Ma, Y., Lee, J.H. and Park, J.W. (2008) Exceedingly Efficient Deep-Blue Electroluminescence from New Anthracenes Obtained Using Rational Molecular Design. Journal of Materials Chemistry C, 18, 3376-3384. http://dx.doi.org/10.1039/b805062g

[17] Bin, J.K. and Hong, J.I. (2011) Efficient Blue Organic Light-Emitting Diode Using Anthracene-Derived Emitters Based on Polycyclic Aromatic Hydrocarbons. Organic Electronics, 12, 802-808. 
http://dx.doi.org/10.1016/j.orgel.2011.02.011

[18] Ting, C.H. (1967) Electronic Structure and Intersystem Crossing in 9,10-Diphenylanthracene. Chemical Physics Letters, 1, 335-336. http://dx.doi.org/10.1016/0009-2614(67)80010-1

[19] Park, J.W., Kim, Y.H., Jung, S.Y., Byeon, K.N. and Jang, S.H. (2008) Efficient and Stable Blue Organic Light-Emitting Diode Based on an Anthracene Derivative. Thin Solid Films, 516, 8381-8385. http://dx.doi.org/10.1016/j.tsf.2008.04.080

[20] Chien, C.H., Chen, C.K., Hsu, F.M., Shu, C.F., Chou, P.T. and Lai, C.H. (2009) Multifunctional Deep-Blue Emitter Comprising an Anthracene Core and Terminal Triphenylphosphine Oxide Groups. Advanced Functional Materials, 19, 560-566. http://dx.doi.org/10.1002/adfm.200801240

[21] Allen, A.D. and Cook, C.D. (1963) Substituted Phenylacetylenes. Infrared Spectra. Canadian Journal of Chemistry, 41, 1084-1087. http://dx.doi.org/10.1139/v63-155

[22] Kukhta, A.V., Kukhta, I.N., Kukhta, N.A., Neyra, O.L. and Meza, E. (2008) DFT Study of the Electronic Structure of Anthracene Derivatives in Their Neutral, Anion and Cation Forms. Journal of Physics B: Atomic, Molecular and Optical Physics, 41, Article ID: 205701. http://dx.doi.org/10.1088/0953-4075/41/20/205701

[23] Birks, J.B. (1975) Excimers. Reports on Progress in Physics, 38, 903-974. http://dx.doi.org/10.1088/0034-4885/38/8/001

[24] Anthony, J.E. (2007) Induced $\pi$-Stacking in Acenes. In: Müller, T.J.J. and Bunz, U.H.F., Eds., Functional Organic Materials: Syntheses, Strategies and Applications, Wiley-VCH Verlag GmbH \& Co. KGaA, Weinheim, 511-542. http://dx.doi.org/10.1002/chin.200735267

[25] Lee, K.-S. (2002) Polymers for Photonics Applications I. Spring-Verlag Berlin Heidelberg, New York.

[26] Ullaa, H., Garudacharib, B., Satyanarayana, M.N., Umesha, G. and Isloorb, A.M. (2014) Blue Organic Light Emitting Materials: Synthesis and Characterization of Novel 1,8-Naphthalimide Derivatives. Optical Materials, 36, 704-711. http://dx.doi.org/10.1016/j.optmat.2013.11.017 